Meta

Journal des traducteurs

Translators' Journal

\title{
La historia de la publicación de los comics de Disney en Italia desde un enfoque traductológico
}

\section{Caterina Bosco}

Volume 60, numéro 2, août 2015

$60^{\mathrm{e}}$ anniversaire. Les horizons de la traduction : retour vers le futur $60^{\text {th }}$ Anniversary. Translation's Horizons: Back to the Future

60mo aniversario. Los horizontes de la traducción: regreso al futuro

URI : https://id.erudit.org/iderudit/1032864ar

DOI : https://doi.org/10.7202/1032864ar

Aller au sommaire du numéro

Éditeur(s)

Les Presses de l’Université de Montréal

ISSN

0026-0452 (imprimé)

1492-1421 (numérique)

Découvrir la revue

Citer ce document

Bosco, C. (2015). La historia de la publicación de los comics de Disney en Italia desde un enfoque traductológico. Meta, 60(2), 313-313.

https://doi.org/10.7202/1032864ar d'utilisation que vous pouvez consulter en ligne. 


\title{
La historia de la publicación de los comics de Disney en Italia desde un enfoque traductológico
}

\author{
Caterina Bosco \\ Universitat Pompeu Fabra, Barcelona, España \\ kabo27@yahoo.it
}

Lo que me propongo en este trabajo es un recorrido por la historia de la traducción de los cómics de Disney en Italia. Este recorrido se entrelaza con la hipótesis de un caso de pseudotraducción, basado en el hecho de que, desde el principio, la publicación de estos cómics ha incluido tiras y, posteriormente, historias enteramente realizadas in loco, o sea, escritas y dibujadas en Italia por autores italianos. Toury afirma que una pseudotraducción es un texto que parece ser una traducción aunque no tenga ningún texto fuente equivalente, ninguna relación de traducción en otros idiomas. De hecho, veremos cómo, durante más de treinta años, las tiras cómicas de Disney publicadas en Italia han salido mezcladas, las importadas y traducidas de los EEUU junto con las domésticas, sin que nada pudiera delatar la diferencia. Se vislumbra por tanto una hipótesis de intervención cultural resultante en la transmisión de un modelo de desarrollo social que, ya implementado en EEUU, fue el que inspiró la recuperación económica de la posguerra en Italia.

Caterina Bosco es doctoranda en Comunicació Lingüística I Mediació Multilingüe en la Universitat Pompeu Fabra de Barcelona. Sus principales campos de interés son la traducción y la adaptación de los cómics, la construcción de la identidad cultural a través de la traducción, la pseudotraducción y el 'cultural planning' en Italia en la posguerra. Recientemente ha publicado (en prensa) «Translation, Pseudotranslation and Adaptation of Disney Comics into Italian Language and Culture" en TransÜD series (2015), Berlin: Frank \& Timme. 